\title{
How do hedge funds manage portfolio risk?*
}

\author{
Gavin Cassar \\ The Wharton School \\ University of Pennsylvania
}

Joseph Gerakos

Booth School of Business

University of Chicago

December 2010

\begin{abstract}
We investigate the determinants and effectiveness of methods that hedge funds use to manage portfolio risk. We find that levered funds are more likely to use formal models to evaluate portfolio risk and funds with higher levels of proprietary capital are more likely to have a dedicated risk officer who has no trading authority. Funds in our sample that use formal models performed better in the extreme down months of 2008 and, in general, had lower exposures to systematic risk. Moreover, funds employing value at risk and stress testing had more accurate expectations of how they would perform in a short-term equity bear market. Overall, our results suggest that models of portfolio risk increase the accuracy of managers' expectations and assist managers in reducing exposures to both systematic and downside risk.
\end{abstract}

\footnotetext{
*Corresponding author: Joseph Gerakos, 5807 S. Woodlawn Avenue, Chicago, IL 60637; telephone (773) 834-6882; e-mail jgerakos@chicagobooth.edu. Gavin Cassar, Steinberg HallDietrich Hall (Suite 1300), 3620 Locust Walk, Philadelphia, PA 19104; telephone (215) 8982023; e-mail cassar@wharton.upenn.edu. We thank The Hedge Fund Due Diligence Group at Analytical Research (HedgeFundDueDiligence.com) for providing the data used in this study and the Global Association of Risk Professionals for providing financial support. We also thank Jeremiah Green, Chris Ittner, Cathy Schrand, Jesse Shapiro and participants at the 2010 Journal of Accounting, Auditing and Finance Conference for their comments. Elizabeth Keller provided excellent research assistance.
} 


\section{Introduction}

We investigate the determinants and effectiveness of methods that hedge funds use to manage portfolio risk. Although there is well developed normative academic literature on how hedge fund should manage risk (for example, see Lo (2001), Jorion (2007), and Jorion (2008)), there are no broad empirical investigations of how hedge funds actually manage portfolio risk and the effectiveness of such practices. To investigate hedge fund risk management practices, we use a proprietary database of due diligence reports prepared by The Hedge Fund Due Diligence Group at Analytical Research (HedgeFundDueDiligence.com), a hedge fund investigation firm. Institutional investors commissioned these reports to better understand fund operations and risks when evaluating potential hedge fund investments. The reports provide extensive detail on fund characteristics, internal operations, and risk management practices. This data set addresses a major impediment to the examination of risk management practices-a lack of cross-sectional data on internal organizational practices (for a discussion, see Tufano (1996)).

Specifically, the reports identify whether the fund employs formal models of portfolio risk (value at risk, stress testing, and scenario analysis), whether the fund's risk officer is dedicated solely to risk management, whether the risk officer has trading authority, and whether the fund employs limits on the concentration of investment positions. In addition, for a subset of funds in our sample, the reports provide managers' expectations of how their fund would perform under extreme financial events such as a short-term equity bear market. These expectations were elicited prior to 2008. We therefore compare expectations with actual fund performance during the equity bear market of September through November 2008.

We find significant heterogeneity in methods that funds use to manage port- 
folio risk. Namely, risk management practices are more extensive for funds that use leverage, hold positions for shorter durations, and hold more investment positions. Specifically, levered funds are more likely to use formal models of portfolio risk, funds that hold large numbers of positions are more likely to have dedicated risk officers with no trading authority, and funds that hold positions for longer durations are less likely to have position limits. Moreover, we find that the likelihood that a fund has either a dedicated head of risk management or a risk officer with no trading authority increases in the fund's proprietary capital, implying that fund managers increase risk oversight when they have more personal wealth invested in their fund.

We posit that risk management practices improve the fund managers' understanding of how changes in the financial environment would affect their fund's performance. Examining performance during the equity bear market that occurred from September through November 2008, we find that managers of funds that use value at risk and stress testing to evaluate portfolio risk appear to have more accurate expectations about how their fund would perform during a short term equity bear market. In contrast, we find no association between the accuracy of expectations and the other risk management practices.

Furthermore, if risk management practices improve managers' understanding of risk exposures, then funds with more extensive risk management should perform better during extreme financial events. Consistent with our thesis, we find that models of portfolio risk are associated with differences in exposures to downside risk. Namely, funds that use formal models of portfolio risk did relatively better in the extreme down months of 2008 than those that do not. The magnitude of these effects are economically significant. For example, in October 2008, funds in our sample that use at least one model of portfolio risk had returns six percent higher than funds that did not use any type of model. 
Consistent with risk models assisting only in extreme periods, we find no differences in performance between funds that do and do not use risk models in 2007 or the first six months of 2009 . We also find that risk models are associated with exposures to systematic risk. With respect to systematic risk exposures, using returns reported over the 30 month period between January 2007 and June 2009, we find that funds using models had significantly lower exposures to systematic risk. Overall, our results suggest that models of portfolio risk increase the accuracy of managers' expectations and assist managers in reducing exposures to both downside and portfolio risk.

An alternative explanation for our findings is that they are driven by selfselection. Namely, funds select risk management practices based on their risk exposures. However, the weight of our evidence points toward risk management practices allowing managers to better understand and monitor portfolio risk for several reasons. First, if self-selection drives our results, then funds investing in riskier and more volatile assets presumably employ stronger risk management practices. In contrast, we find that the monthly returns of funds that use models have significantly lower volatilities. Second, examining the skewness of returns, we find that the October 2008 returns of funds that do not use models are more negatively skewed than the returns of funds that employ models of portfolio risk, suggesting that funds that do not use models face greater left tail risk and that differences in performance are not driven by a mean shift in returns. Third, while we find funds that use formal models perform better during the shortterm equity bear markets, we find no significant differences in the performance of hedge funds with different risk management practices during 2007 and the first six months of 2009. Fourth, the associations between performance and risk management practices are robust to the inclusion of the determinants of risk management and investment style in the multivariate tests. Moreover, the 
magnitude of the point estimates on the risk management measures are similar in the univariate and multivariate tests, further suggesting that our results are not driven by unobservable heterogeneity.

This study contributes to both the risk management literature and to the growing literature on the internal operations of hedge funds. With respect to the risk management literature, we examine the voluntary adoption of risk management practices in an unregulated setting. Prior research focuses on a limited set of choices such as the choice of hiring a chief risk officer or the hedging of commodity prices and/or interest rates made by bank holding companies, regulated utilities, and other SEC registrants (for example, see Liebenberg and Hoyt (2003), Geczy et al. (1997), and Geczy et al. (2007)). In contrast, our proprietary data set and empirical setting enable us to investigate a broader set of risk management practices in a domain for which there is minimal academic research on how organizations manage risk. Moreover, we contribute to the risk management literature by examining outcomes from risk management.

We also contribute to the risk management literature by examining the accuracy of fund managers' expectations of future performance, and the extent to which risk management practices improve the accuracy of such expectations. Outside of the management earnings forecast literature, there is minimal empirical evidence that compares manager's expectations of performance with $e x$ post realizations, and none on either hedge funds or organizational performance given changes in the economy (for a discussion, see Cassar and Gibson (2008)). In doing so, we provide evidence of a specific benefit of better risk management practices - namely, increasing the accuracy of expectations.

With respect to the literature on hedge funds, we extend the literature on the internal operations of hedge funds. Due to a lack of data, there is minimal academic research on the internal structures and operations of hedge funds, 
especially on how they manage portfolio risk. Nevertheless, Jorion (2000) and Lo (2001) conjecture that the risk management practices used in other financial services firms are not applicable to hedge funds given their atypical nature. Furthermore, Lo (2001) conjectures that investors and managers of hedge funds historically devoted little attention to active risk management practices. Despite these conjectures, we find that find that many funds implement portfolio risk management practices and that these practices are associated with differences in exposures to downside and systemic risk, and the accuracy of expectations.

Finally, regulators of financial markets have an interest in the extent that fund managers understand their exposures to financial risks. As discussed by Chan et al. (2007), the Senior Supervisors Senior Supervisors Group (2008), and Ellul and Yerramilli (2010), in light of the recent crisis, a primary concern of regulators is the extent that inadequate risk management practices affect the stability of financial markets. Although there has been substantial growth in the hedge fund industry, both in the number of funds and in assets under management (for a discussion, see Lo (2007)), there is limited research on how hedge funds manage portfolio risk and the extent that such practices prevented or exacerbated investment choices that contributed to the recent the financial crisis. Our results suggest that models of portfolio risk reduced investment choices that could have contributed to the crisis.

\section{Sample}

Hedge funds are managed investment vehicles. Some stylistic features of hedge funds include: they are often privately held, generally comprised of wealthy individuals and institutional investors, and typically organized in the U.S. as limited partnerships and offshore as corporations (Fung and Hsieh (1999)). Hedge funds are structured to be exempt from the Securities Exchange 
Acts of 1933 and 1934, and the registration requirements of the Investment Company and Advisor Acts of 1940 (Oesterle (2006)). ${ }^{1}$ This minimal regulatory environment provides hedge funds with substantially greater discretion in their operations compared to regulated investment vehicles, such as mutual funds (McVea (2008)).

To investigate the risk management practices of hedge funds, we use a database of proprietary due diligence reports from HedgeFundDueDiligence.com. ${ }^{2}$ Institutional investors commissioned these due diligence investigations to better understand fund operations and risks when evaluating potential hedge fund investments. Consequently, this sample represents a set of hedge funds that were actively seeking to capital. The vendor obtains the information contained in these reports from several sources, including on-site visits and interviews with key staff, discussions with service providers, and review of offering memorandums. These reports provide an extensive array of detail regarding fund and manager characteristics, portfolio characteristics, contract terms, risk beliefs, and risk management practices. This database of due diligence reports provides a comprehensive resource of hedge fund managerial practices and is similar to recent research that uses survey-based data sets to examine managerial practices in publicly traded corporations (for examples, see Graham and Harvey (2001), Brav et al. (2005), and Graham et al. (2005)).

Our sample consists of 427 funds run by 358 unique managers investigated from 2003 to 2007. Table 1 provides descriptive statistics for our sample funds. The mean (median) fund has $\$ 305$ million ( $\$ 107$ million) in assets under management and is, on average, less than three years old (1,020 days) at the time of due diligence.

\footnotetext{
${ }^{1}$ The ability of managers to structure funds so that they are exempt from registration may end in the near future given that the Dodd-Frank Act requires large hedge fund advisors to register with the SEC. The specifics of such registrations have yet to finalized by the relevant regulatory bodies.

${ }^{2}$ Brown et al. (2009) and Cassar and Gerakos (2010a) also use this database.
} 
To examine the effectiveness of the various hedge fund risk management practices, we merge these funds with monthly returns reported on the three major hedge fund returns commercial databases: Lipper TASS, Hedge Fund Research, and CISDM (for a discussion of these databases, see Agarwal et al. (2007)). Where funds report to multiple databases, we obtain returns first from the Lipper TASS database, then Hedge Fund Research, and finally CISDM. Of our sample funds, 114 have a full set of monthly reported returns over the period January 2007 through December 2008 on at least one of these three databases. Although compared to prior research on hedge funds this is a small sample, these 114 funds held over $\$ 48$ billion in assets under management at the time of due diligence.

\section{Risk management practices}

We define portfolio risk management practices as those procedures and mechanisms that monitor or manage an organization's exposure to portfolio risk. ${ }^{3}$ We examine three sets of risk management practices: 1) the use of models to quantify and evaluate portfolio risk; 2) the presence of a dedicated head of risk management and the extent that the head of risk management has trading authority; 3 ) the use of limits on the concentration of investment positions. Table 2 reports the descriptive statistics for these risk management practices. The scope of investigation by the due diligence firm expanded during our sample period. Consequently, the number of non-missing responses varies across the risk management practices, with some responses only available for later observations. We report both the full sample used to estimate the determinants of various risk management practices and the subset of funds that have reported monthly returns from January 2007 to December 2008. Univariate t-tests reveal no significant differences in the risk management practices between reporting

\footnotetext{
${ }^{3}$ For research on hedge fund operational risk, see Brown et al. (2008).
} 
and non-reporting funds.

\subsection{Models}

The vendor queried sample funds about their use of three types of models to evaluate portfolio risk: value at risk, stress testing, and scenario analysis. As discussed by Jorion (2000), value at risk measures the maximum expected loss that can occur over a specified period at a specified quantile. Jorion (2010), however, points out that value at risk has several limitations that are problematic for hedge fund portfolios. First, value at risk assumes that the fund's portfolio is static, while funds typically follow dynamic trading strategies. Second, value at risk assumes that the fund is a price taker. But, if the fund is forced to liquidate a large position, prices could move adversely thereby leading to a larger loss than indicated by value at risk. Therefore, funds often use two additional types of models that allow managers to examine potential extreme events. Stress testing identifies how the portfolio would respond to large shifts in relevant economic variables or risk parameters. Scenario analysis assesses how the portfolio would respond to severe but plausible scenarios, such as significant changes in interest rates or liquidity. Given the similarities among the three types of models, for our empirical tests we also create a measure of whether the fund uses at least one model. We find that 43.7 percent of funds employ value at risk, 52.1 percent use stress testing, and 46.4 percent use scenario analysis. Over half the sample ( 58.3 percent) employ at least one modeling approach and 36.4 percent of all funds employ all three modeling approaches.

\subsection{Head of risk management}

Funds were asked to identify who was their head of risk management. They were further asked whether this person was dedicated to risk management or part of the primary management team. In our sample, 34.0 percent of funds have

an executive dedicated to risk management. In the remaining 66.0 percent of 
funds, individuals were only partly dedicated to risk management and undertook other investing or administrative functions. With respect to the extent of their trading authority, for 70.1 percent of the funds the head of risk management had full trading authority, while 4.2 percent had authority to invest only for hedging purposes. The remaining 25.8 percent had no trading authority.

\subsection{Position limits}

The due diligence reports also provide substantial detail regarding the use of investment position limits. For this practice, we ignore all zero limits, (e.g., the fund is does not undertake investments in a particular asset class) and focus on the use of non-zero limits in which the fund is actively investing. We find that 16.6 percent of our hedge funds have hard limits on the dollar amount or proportion of their portfolio that they are allowed to hold in a specific position. We also find 26.9 percent of funds, while not having hard limits, employ investment guidelines on the amount or proportion that can be invested in a given position. The remaining 56.4 percent of funds have neither hard limits or guidelines for their investments.

\subsection{Measures of risk management practices}

For our empirical tests, we code all dichotomous responses to yes/no questions as 1 for "yes" and 0 for "no." We further rank order variables $(0,1,2)$ where there is a natural ordering of risk management practices. For example, we code the trading authority of the head of risk management as follows: 0 for full trading authority; 1 for hedging authority; 2 for no trading authority. And, we code positions limits as follows: 0 for no limits; 1 for guidelines; 2 for hard limits.

\section{Determinants of risk management practices}

We argue that risk management practices provide a hedge fund manager 
with better monitoring and a more precise understanding of the fund's risk exposures. While hedge funds are mandated to take financial risks, funds typically attempt to limit their exposure to the specific risks outlined in their offering documents. For example, some funds follow a market-neutral investment strategy, whereby managers attempt to limit the fund's exposure to systematic risk. We posit that risk management practices assist managers in both monitoring and reducing their funds' exposures to risks that are not included in their mandate. Furthermore, as discussed by Cassar and Gibson (2008), formalized approaches to forecasting can increase accuracy of managers' expectations of their firms' performance. We therefore posit that risk management practices increase the accuracy of fund manager's expectations of how the fund's performance would be affected by changes in the fund's operating environment.

Given these posited benefits, we predict that the demand for risk management practices is a function of fund characteristics including: leverage, fund size, the manager's wealth invested in the fund, and reputation. First, leverage increases the fund's exposure to changes in asset values. Moreover, large losses can lead to margin calls from lenders and investor redemptions, both of which can force the manager to quickly liquidate the portfolio at "fire sale" prices. Therefore, all else equal, levered funds receive greater benefits from investments in risk management. We therefore predict a positive association between risk management investments and leverage. To measure leverage, we include an indicator for whether the fund uses explicit leverage as opposed implicit leverage derived from derivatives.

Second, the greater the amount of assets at risk, the greater the benefit from understanding and monitoring portfolio risk. Furthermore, the marginal cost of implementing and operating risk management practices likely decreases in fund scale. Therefore, we predict that risk management practices increase with 
fund size. Furthermore, size also captures quality, because better performing funds generally receive higher capital flows. For measure size, we use the natural logarithm of investor assets.

Third, fund managers often invest a substantial proportion of their personal wealth in their fund. Given managerial risk aversion, when managers have substantial wealth invested in their funds they have incentives to implement more extensive risk management practices to better understand and monitor risk exposures. Consequently, we predict a positive association between proprietary capital and risk management practices. To measure proprietary capital, we use the natural logarithm of proprietary assets, which represent personal investments in the fund made by the managers and employees.

Fourth, managers of established funds possess valuable reputations. Therefore, managers of more reputable funds have more to lose, such as their ability to charge higher fees, start new funds, or keep existing investors, should substantial changes in the value of the funds invested assets occur to due to unexpected risk exposures. Consequently, we posit that older funds have better risk management practices. Furthermore, fund age and risk management practices can be positively correlated if risk management increases the likelihood of fund survival. To proxy for reputation, we use the natural logarithm of fund age as of the date of the report from the due diligence investigation.

In our empirical tests, we include several variables to proxy for portfolio characteristics. We take these variables directly from the due diligence reports. First, we include indicator variables for whether the portfolio is long or short biased. Second, we include indicator variables that capture the number of typical positions that the fund holds (1-39 Positions, 40-99 Positions, 100-199 Positions, 200-999 Positions, and 1000+ Positions) and the typical duration that the fund holds a position (Days, Weeks, Months, Quarters, and Years). These 
variable allow us to control for trading strategies that are likely correlated with risk management practices. For example, quantitative hedge funds typically hold thousands of positions for short periods.

Table 3 reports the Pearson correlation between the risk management practices and the fund and portfolio characteristics. Many of the risk management practices are positively correlated with each other. For example, the correlations among three types of models are all greater than 0.70 , their correlation with the head of risk management measures are all greater than 0.20 . There are also significant univariate correlations between the risk management practices and the independent variables. The active use of leverage is positively and significantly correlated with models, limits on the trading authority of the head of risk management, and position limits.

Table 4 presents marginal effects from estimates of probit regressions that model the determinants of the use of models of portfolio risk. For all approaches examined, models are more likely to be employed in funds that use leverage, engage in a long bias investment strategy, and make investments over shorter duration. These effects are economically significant. For example, funds that use leverage are 17 percent more likely to use at least one model and funds whose portfolios are long biased are 21 percent more likely to use at least one model. We do not, however, find a similar association between short bias and formal models. Consistent with prior research on the risk management practices of nonfinancial firms (for example, see Liebenberg and Hoyt (2003)), the coefficient on leverage is positive and significant.

Table 5 presents estimates from a probit model and an ordered probit model that examine the determinants of whether the fund's risk officer is dedicated to risk management and whether the head of risk management has trading authority. Holding the amount of capital provided by outside investors constant, we 
find that funds with greater proprietary assets are more likely to dedicate a team to risk management and less likely to give the head of risk management trading authority. Both findings are consistent with fund managers implementing more extensive risk management practices when they have greater personal wealth invested in their fund. In contrast, we find no such associations between risk officer characteristics and the capital provided by outside investors. In addition, younger funds and levered funds are less likely to give the trading authority to the head of risk management.

Finally, as shown in Table 6, funds that have more investor assets, older funds, and off-shore funds are more likely to have position limits in place. In addition, funds that hold many positions and funds that hold their positions for typically more than a week are less likely to implement position limits. Overall, we find substantial heterogeneity in the extent that hedge funds implement portfolio risk management practices.

\section{$5 \quad$ Accuracy of expectations}

In this section, we examine the extent that risk management practices are associated with the accuracy of manager expectations of how their fund will perform during periods of extreme financial events. Effective risk management can facilitate both understanding the implications from changes in the external environment (financial markets) and preventing unforeseen changes in performance from changes in the external environment. We posit that better risk management practices improve the fund managers' understanding of how their fund's performance is affected by changes in the financial environment. Consequently, we predict that funds employing better or more appropriate risk management practices have more accurate expectations about their fund performance.

The vendor queried managers about their expectation of their fund's perfor- 
mance during a short-term (one month) equity bear market, which as classified into five categories: $-2=$ "Down"; $-1=$ "Down (a little)"; $0=$ "No effect"; $1=$ "Up (a little)"; 2 = "Up."" The last due diligence reports was completed in August, 2007. Table 7 presents the distribution of managers' expectations and classifies the funds by their risk management practices. As shown in the table, there do not appear to be systematic relations among the risk management practices and expectations. Moreover, Chi-square tests confirm that there are no significant differences.

We observe two interesting features of the manager expectations. First, we observe substantial heterogeneity in the manager's expectations to how their fund would perform in a short-term equity bear market. For example, 27.5 percent (44.5 percent) of fund managers expect their fund performance to improve (worsen) during a one-month equity panic. Second, many (28 percent) hedge fund managers believe that their fund returns are neutral or not exposed to a sharp decline in financial equity markets. This finding reflects the specificity of the investments made by hedge funds, or a miscalibration of manager expectations.

To measure the accuracy of managers' expectations, we use short-term equity bear market that occurred during the the months of September, October, and November 2008. Over these months, the S\&P 500 lost 9, 17, and 7 percent. We aggregate performance over these three months for two reasons. First, it is not clear that each month represents a separate short-term equity bear market. Second, prior research finds that hedge fund managers appear to spread negative returns over several months to smooth reported performance (for examples, see Bollen and Pool (2008) and Cassar and Gerakos (2010b)).

Figure 1 plots mean and median performance over this period grouped by

\footnotetext{
${ }^{4}$ Later in the sample period, HedgeFundDueDiligence.com increased the categories to include -3 "Down a lot" and +3 "Up a lot." We coded such responses as -2 and +2 .
} 
expected fund performance. If fund managers are accurate in the expectations of their fund's performance during a short-term equity bear market we would observe the mean and median fund performance increasing in expected performance. In general, there is a minimal, at best, association between the manager's expectation and actual performance for the full sample.

We next examine whether models are associated with the accuracy of expectations. In Figures 2 through 4, we split the sample by funds that use the different types of models and those that do not. For each type of model, we compare both the mean and median performances conditional on the manager's expectation. Figure 2 shows that, in general, expectations are more accurate for funds that use value at risk to model portfolio risk. Figure 3 shows a slight relationship for stress testing. In contrast, as shown in Figure 4, there appears to be no relationship for funds that use scenario analysis. These findings suggest that value at risk, and to a lesser extent stress testing, appear to result in more accurate manager expectations.

Next, we examine the association between the manager's expectation and actual performance by the characteristics and responsibilities of the head of risk management and by whether the fund had limits on their investment positions. In unreported analyses, we find no association between manager accuracy and these risk practices. Overall, we conclude that the accuracy benefits obtained from risk management practices are driven by the use of models.

\section{Downside risk and systematic risk}

In this section, we examine two potential benefits of models. First, we examine whether funds using models have lower downside risk. Namely, do they perform relatively better when the equity market experiences significant drops? Second, we examine whether funds using models have lower systematic 
risk.

\subsection{Downside risk}

Our first set of tests examines whether there are differences in monthly relative performance over 2008 between funds that use and do not use formal models of portfolio risk. Table 8 presents univariate comparisons for 2008 and Table 9 presents multivariate comparisons. In the multivariate tests, we include all of the independent variables used to model the determinants of risk management practices (as presented in Tables 4 through 6) along with indicator variables for the fund's investment style, which are based on the Lipper TASS and HFR style designations. At the top of each table we present the month's return for the S\&P 500 Index and the HFR Composite Index of hedge fund returns.

Consistent with models reducing downside risk, for each months in which the S\&P 500 Index had a return of less than negative five percent, in Table 9 all of the coefficients on models are significantly positive. In addition, the coefficients on models are significantly positive for July and August, even though S\&P 500 performance was slightly positive and slightly negative for these two months. Note, however, that the HFR Composite Index was negative for both July and August.

The lower downside risk of hedge funds using formal models could indicate overall differences in performance that are driven unobserved manager ability, which is correlated with risk management practices. To investigate this issue, in in Table 10, we examine whether there are similar associations with performance during 2007 and the first six months of 2009. As shown in Table 10, for these periods, we find no associations between models and performance for these periods, suggesting that models do not represent mean differences in performance but instead represent differences in exposures to downside risk. Furthermore, in untabulated tests we find that the other risk management practices are not 
associated with performance suggesting that our results are specific to models and do not reflect funds' general risk cultures.

Finally, to further control for investment style, we limit our sample to the style that did the worst in the S\&P 500 down months of 2008, namely long-short equity funds. As shown in Tables 11 and 12, for this subset of funds we find similar results in terms of sign and significance as those presented in Tables 8 and 9 .

\subsection{Systematic risk}

In our final set of tests, we examine whether models are associated with exposures to systematic risk. As discussed by Asness et al. (2001), a major concern for investors is that a hedge fund has significant exposures to systematic risk. Namely, the fee structures of most hedge funds $(2$ percent management fee and 20 percent performance fee) likely do not justify significant exposures to systematic risk, which investors can obtain relatively cheaply in the futures or ETF markets.

Figure 5 compares the distributions of beta for funds that do and do not use formal models of portfolio risk. For each of the 112 funds with sufficient returns, we estimated its beta over the 30 month period starting January 2007 and ending June 2009 using the monthly return on the S\&P500 Index to proxy for the market return. For all three types of models, the mass of the distribution is shifted to the right for funds that do not use models. These differences are statistically significant at the mean and median. Table 13 presents estimates of ordinary least squares estimates of the differences in betas that control for investment style and portfolio characteristics. In these multivariate tests, the mean differences in betas remain statistically significant and similar in magnitude to the univariate estimates. Overall, these results show that funds using formal models have lower exposures to systematic risk. 


\subsection{Alternative explanations}

There are several alternative explanations for the results presented in the section. One potential explanation is that models proxy for a fund's overall investment in risk management. For example, the underlying risk culture at an institution could determine both the risk of the investments and the strength of the institution's risk management practices. As discussed by Ellul and Yerramilli (2010), if general risk culture drives our results, then there should be correlations between all of the risk management practices and performance. We find no such relationships. It therefore appears unlikely that these results are driven by such an omitted correlated variable.

A potential explanation for our performance results is that riskier funds choose models. Several factors point against this selection-based explanation. First, as shown in Figure 6, the returns for funds that do not use models are more negatively skewed for October 2008, suggesting that riskier funds do not select models. In addition, as shown in Figure 7, the monthly return volatility over the period January 2007 through June 2009 is greater for funds that do not use models. These differences in volatility are statistically significant at the mean and median, and when we control for investment style and portfolio characteristics, further suggesting that this form of selection does not drive our results.

Selection, however, could be in the opposite direction. Namely, our results could be explained by less risky funds choosing models. But, models require investments of both managerial effort and financial resources. These non-trivial costs raise the question of why less risky funds would be more likely to make such investments, given that the marginal benefit of such investments is presumably lower for less risky funds. We cannot, however, rule out the possibility that the use of models is negatively correlated with the extent that a fund writes out- 
of-the-money put options (or, euphemistically, provides "liquidity"). The large negative returns in the down months of 2008 for funds that do not use models are consistent with the performance of such strategies. To the extent that this explanation is descriptive of our results, we provide evidence on the incidence of such strategies.

\section{Conclusion}

We investigate the determinants and effectiveness of several methods that hedge funds use to manage portfolio risk. By doing so, we report the first broad empirical investigation of how hedge funds manage portfolio risk and overcome a major impediment to the examination of risk management practices, namely the lack of cross-sectional data on internal organizational practices.

We find that use of various risk management practices are a function of the fund characteristics, such as leverage, number of positions, and the capital invested by the fund managers. Moreover, we document that funds employing formal models to evaluate portfolio risk have more accurate expectations. Therefore, we provide evidence of a novel benefit of better risk management practices - namely, assisting managers in monitoring and better understanding the risks faced by their portfolio. We also find that funds using formal models have less volatile monthly returns, less skewness in monthly returns, significantly better performance during periods of distress, and significantly lower exposures to systematic risk. Overall, our results suggest that models of portfolio risk, but not the other risk management practices, increase the accuracy of managers' expectations and assist managers in reducing exposures to systematic and downside risks. 


\section{References}

Agarwal, V., Daniel, N., Naik, N., 2007. Why is Santa so kind to hedge funds? The December return puzzle! Unpublished working paper, London Business School.

Asness, C., Krail, R., Liew, J., 2001. Do hedge funds hedge? Journal of Portfolio Management Fall, 6-19.

Bollen, N., Pool, V., 2008. Conditional return smoothing in the hedge fund industry. Journal of Financial and Quantitative Analysis 43, 267-298.

Brav, A., Graham, J., Harvey, C., Michaely, R., 2005. Payout policy in the 21st century. Journal of Financial Economics 77 (3), 483-527.

Brown, S., Goetzmann, W., Liang, B., Schwarz, C., 2008. Mandatory disclosure and operational risk: Evidence from hedge fund registration. Journal of Finance 63 (6), 2785-2815.

Brown, S., Goetzmann, W., Liang, B., Schwarz, C., 2009. Trust and delegation. Unpublished working paper, New York University.

Cassar, G., Gerakos, J., 2010a. Determinants of hedge fund internal controls and fees. The Accounting Review, forthcoming.

Cassar, G., Gerakos, J., 2010b. Hedge funds: Pricing controls and the smoothing of self-reported returns. Unpublished working paper, University of Chicago Booth School of Business.

Cassar, G., Gibson, B., 2008. Budgets, internal reports and manager forecast accuracy. Contemporary Accounting Research 25 (3), 707-737.

Chan, N., Getmansky, M., Haas, S., Lo, A., 2007. Systemic risk and hedge 
funds. In: Carey, M., Stulz, R. (Eds.), The Risks of Financial Institutions. NBER, Cambridge, MA, pp. 235-338.

Ellul, A., Yerramilli, V., 2010. Stronger risk controls, lower risk: Evidence from U.S. bank holding companies. Unpublished working paper, NBER.

Fung, W., Hsieh, D., 1999. A primer on hedge funds. Journal of Empirical Finance 6 (3), 309-331.

Geczy, C., Minton, B., Schrand, C., 1997. Why firms use currency derivatives. Journal of Finance 52 (4), 1323-1354.

Geczy, C., Minton, B., Schrand, C., 2007. Taking a view: Corporate speculation, governance, and compensation. Journal of Finance 62, 2405-2443.

Graham, J., Harvey, C., Rajgopal, S., 2005. The economic implications of corporate financial reporting. Journal of Accounting and Economics 40 (1-3), $3-73$.

Graham, J. R., Harvey, C. R., 2001. The theory and practice of corporate finance: Evidence from the field. Journal of Financial Economics 60 (2-3), $187-243$.

Jorion, P., 2000. Risk management lessons from Long-Term Capital Management. European Financial Management 6 (3), 277-300.

Jorion, P., 2007. Risk Management for Hedge Funds with Position Information. Journal of Portfolio Management 34 (1), 127-134.

Jorion, P., 2008. Risk Management for Event-Driven Funds. Financial Analysts Journal 64 (1), 61-73.

Jorion, P., 2010. Risk management. Annual Review of Financial Economics, forthcoming. 
Liebenberg, A., Hoyt, R., 2003. The determinants of enterprise risk management: Evidence from the appointment of chief risk officers. Risk Management and Insurance Review 6 (1), 37-52.

Lo, A., 2001. Risk management for hedge funds: Introduction and overview. Financial Analysts Journal 57 (6), 16-33.

Lo, A., 2007. Hedge Funds: An Analytic Perspective. Princeton University Press, Princeton, NJ.

McVea, H., 2008. Hedge fund asset valuations and the work of the International Organization of Securities Commissions (IOSCO). International and Comparative Law Quarterly 57 (1), 1-24.

Oesterle, D., 2006. Regulating hedge funds. Entrepreneurial Business Law Journal $1,1-42$.

Senior Supervisors Group, 2008. Observations on Risk Management Practices during the Recent Market Turbulence. Staff report.

Tufano, P., 1996. Who manages risk? An empirical analysis of risk management practices in the gold mining industry. Journal of Finance 51 (4), 1097-1137. 
Figure 1: Accuracy of expectations of fund performance during a short-term equity bear market

This Figure plots mean and median fund cumulative performance for September through November 2008 (y-axis) against the manager's expected performance in a short-term equity bear market (x-axis) for the 90 funds with sufficient returns and expectations data. The scale for expected performance in a short-term equity bear market is as follows: $-2=$ "Down"; $-1=$ "Down (a little)"; $0=$ "No effect"; 1 = "Up (a little)"; 2 = "Up."

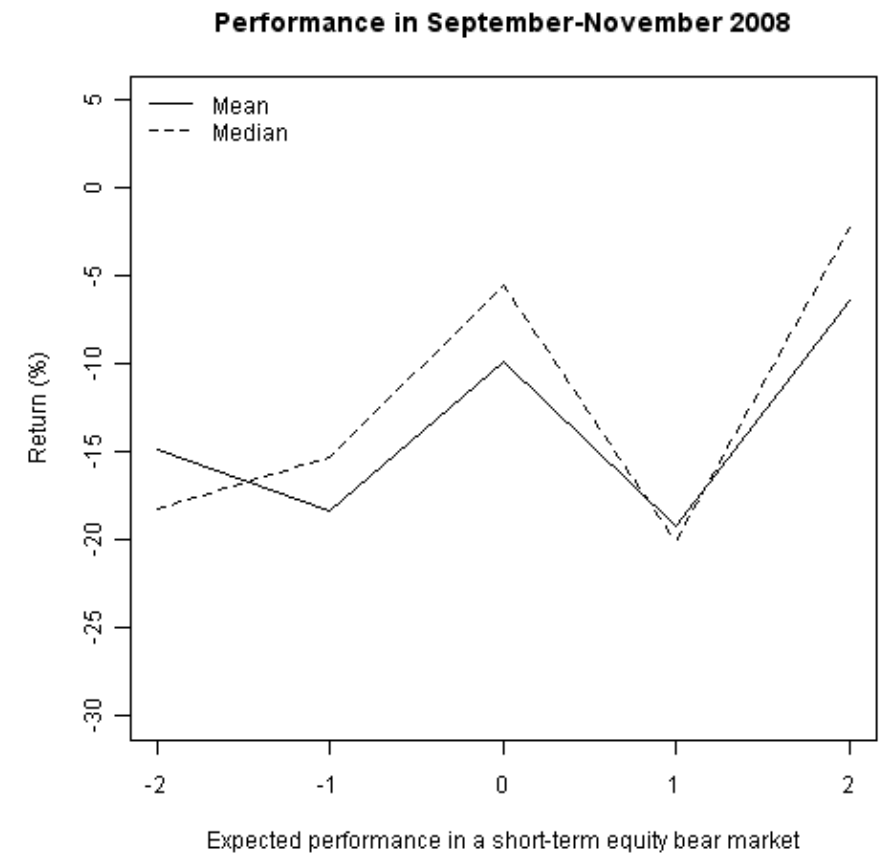



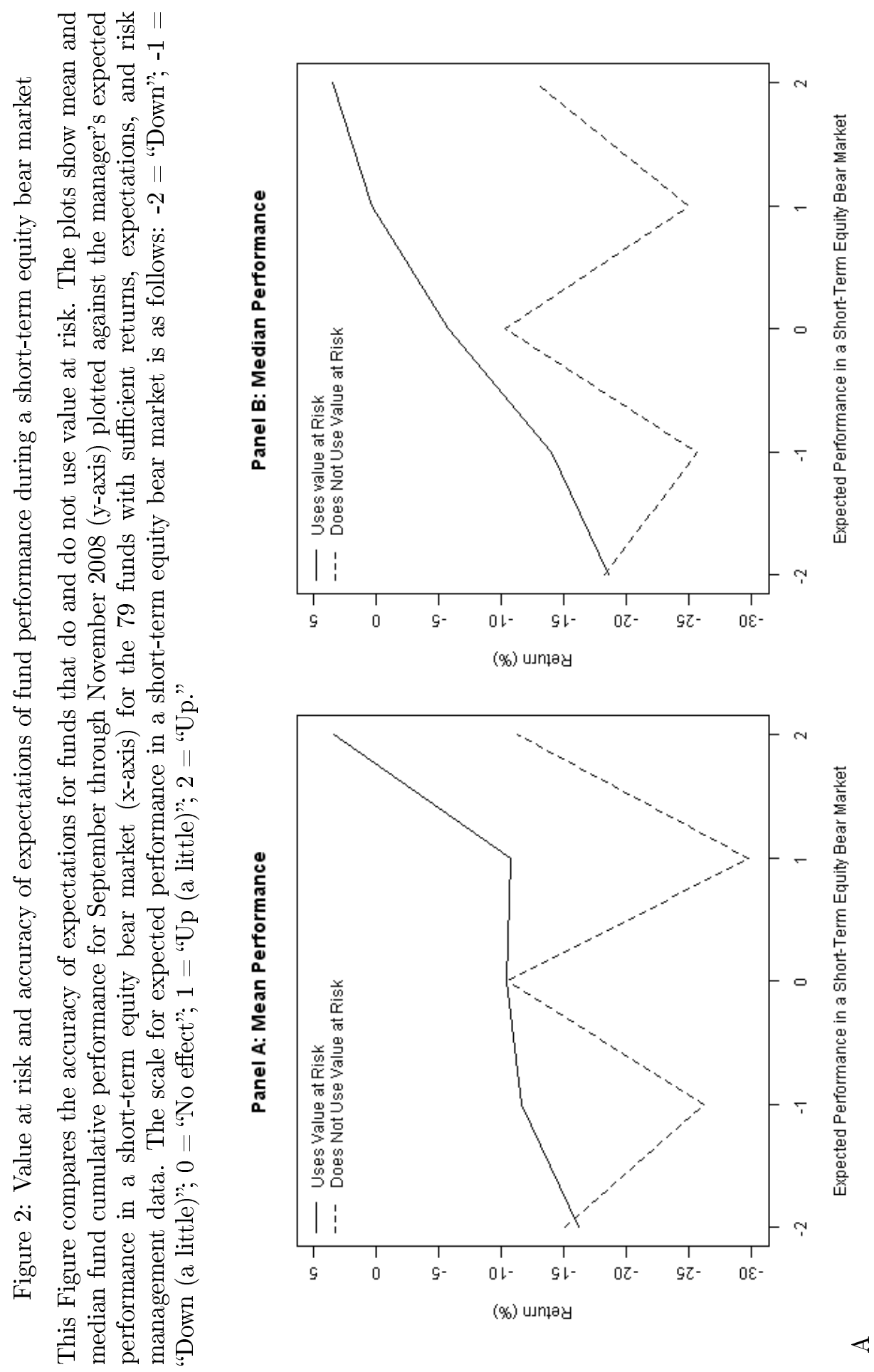

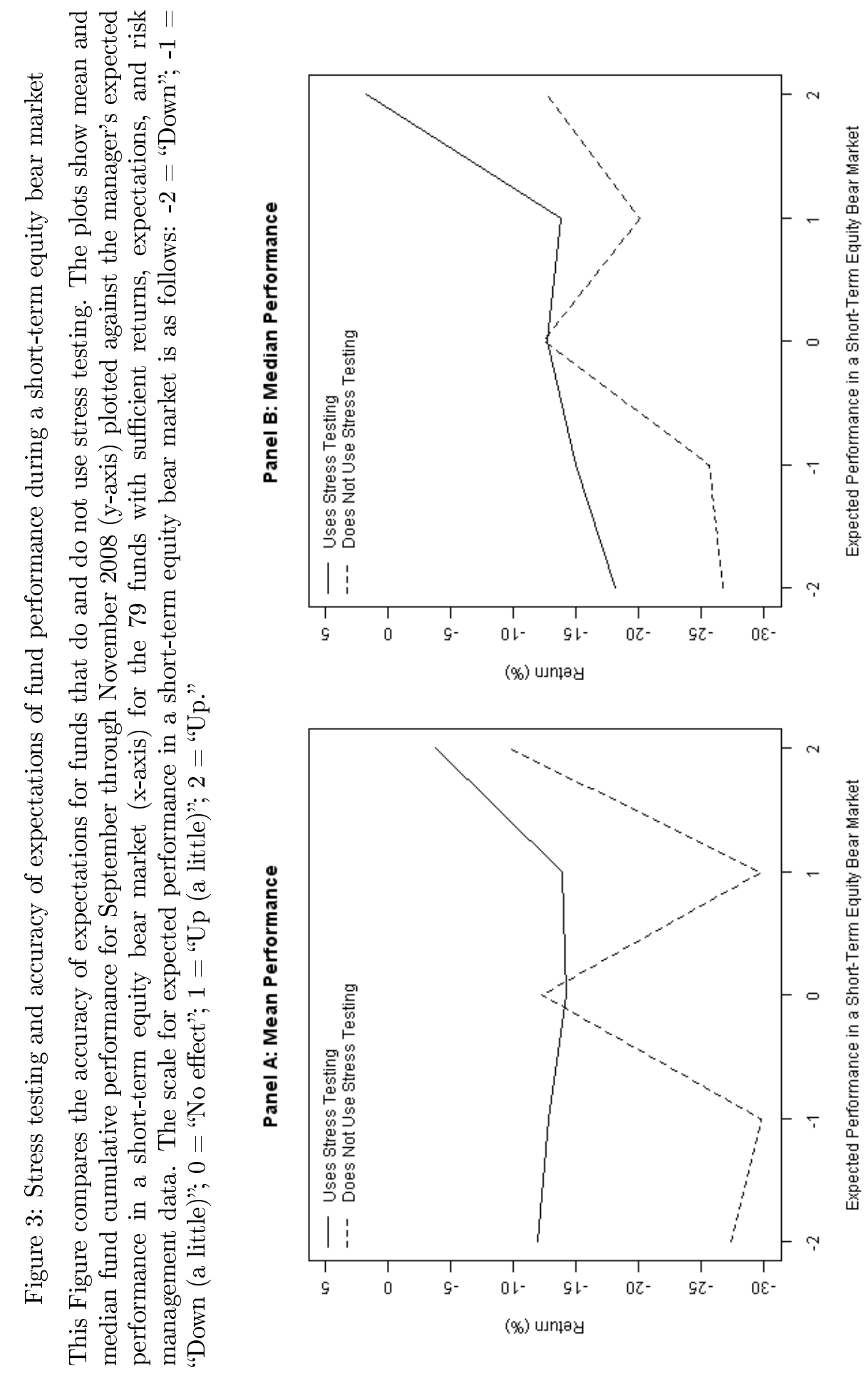

(\%) uлпұау

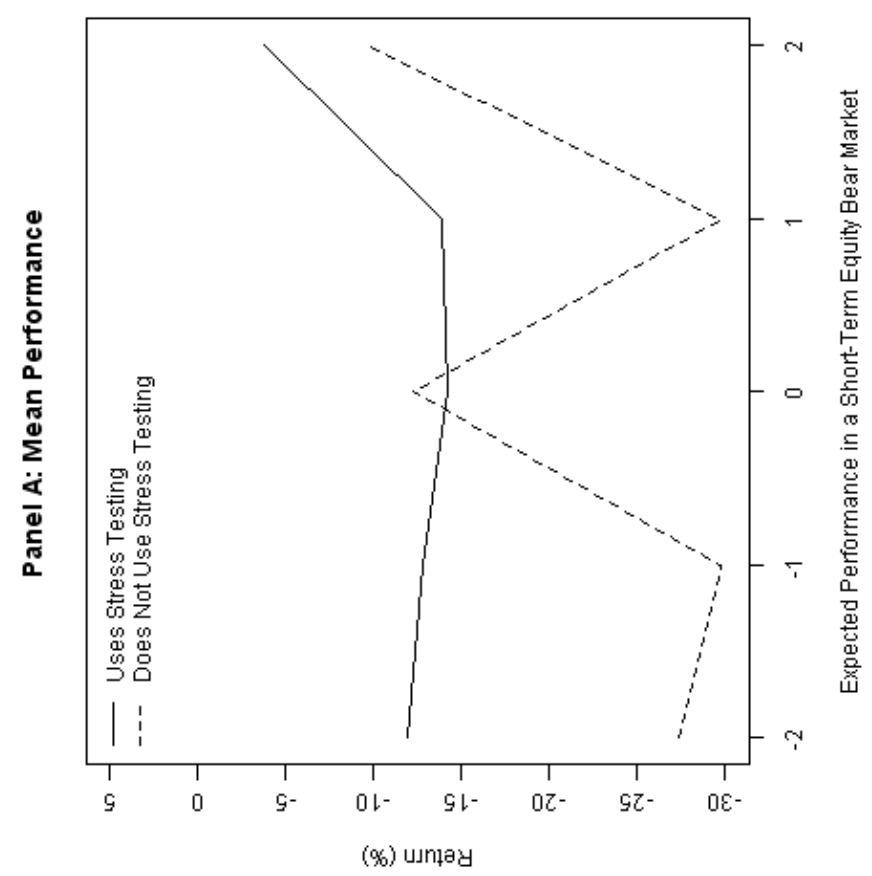



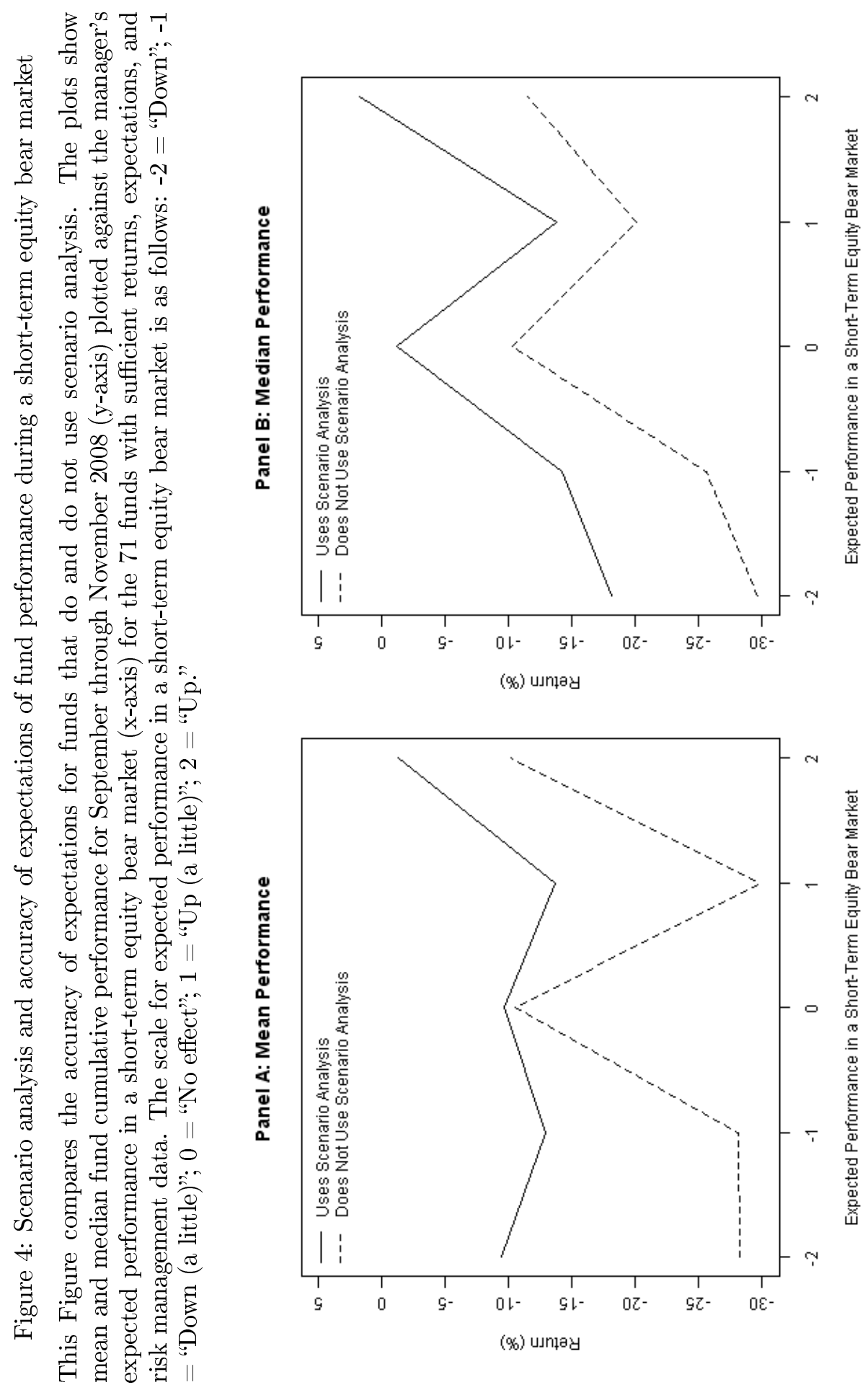

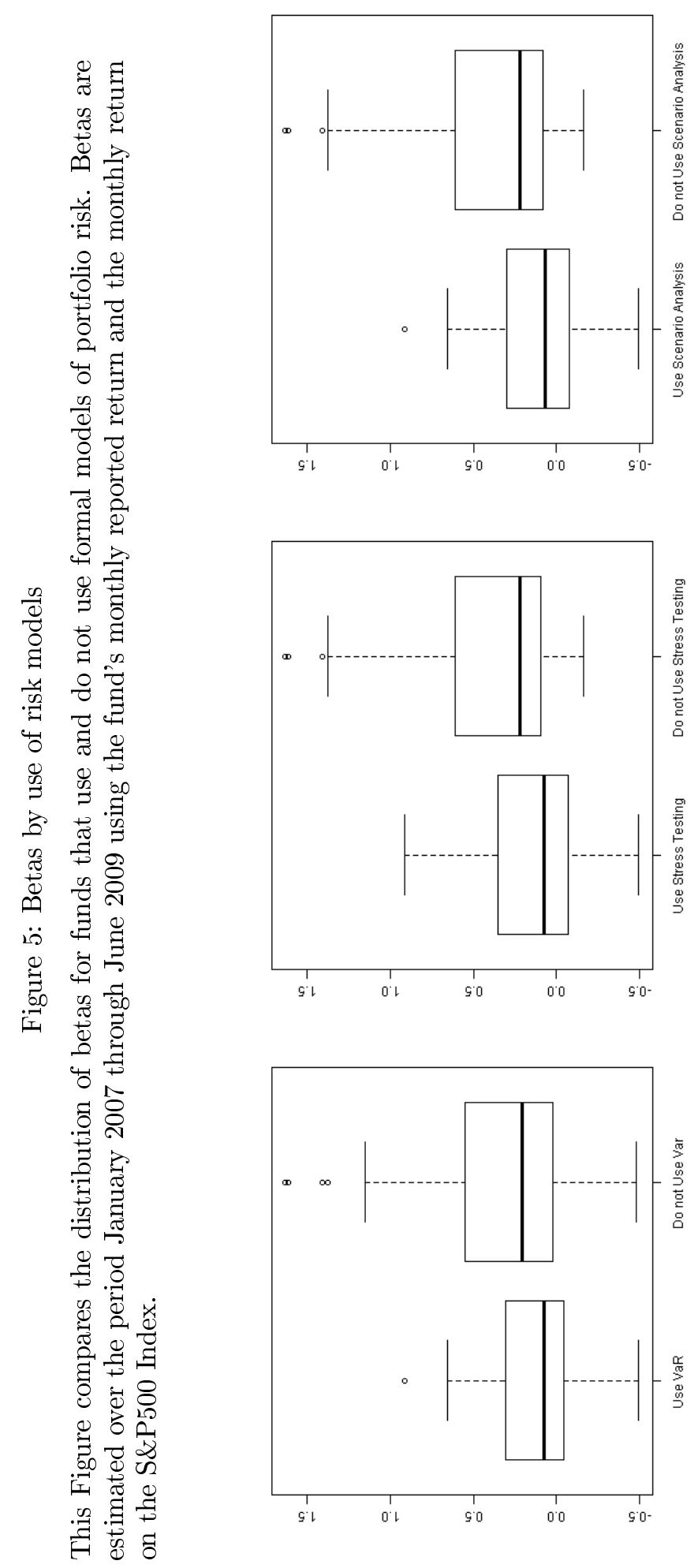
Figure 6: Distributions of returns for October 2008

This Figure compares the monthly distributions of returns for October 2008 for funds that use and do not use formal models of portfolio risk.
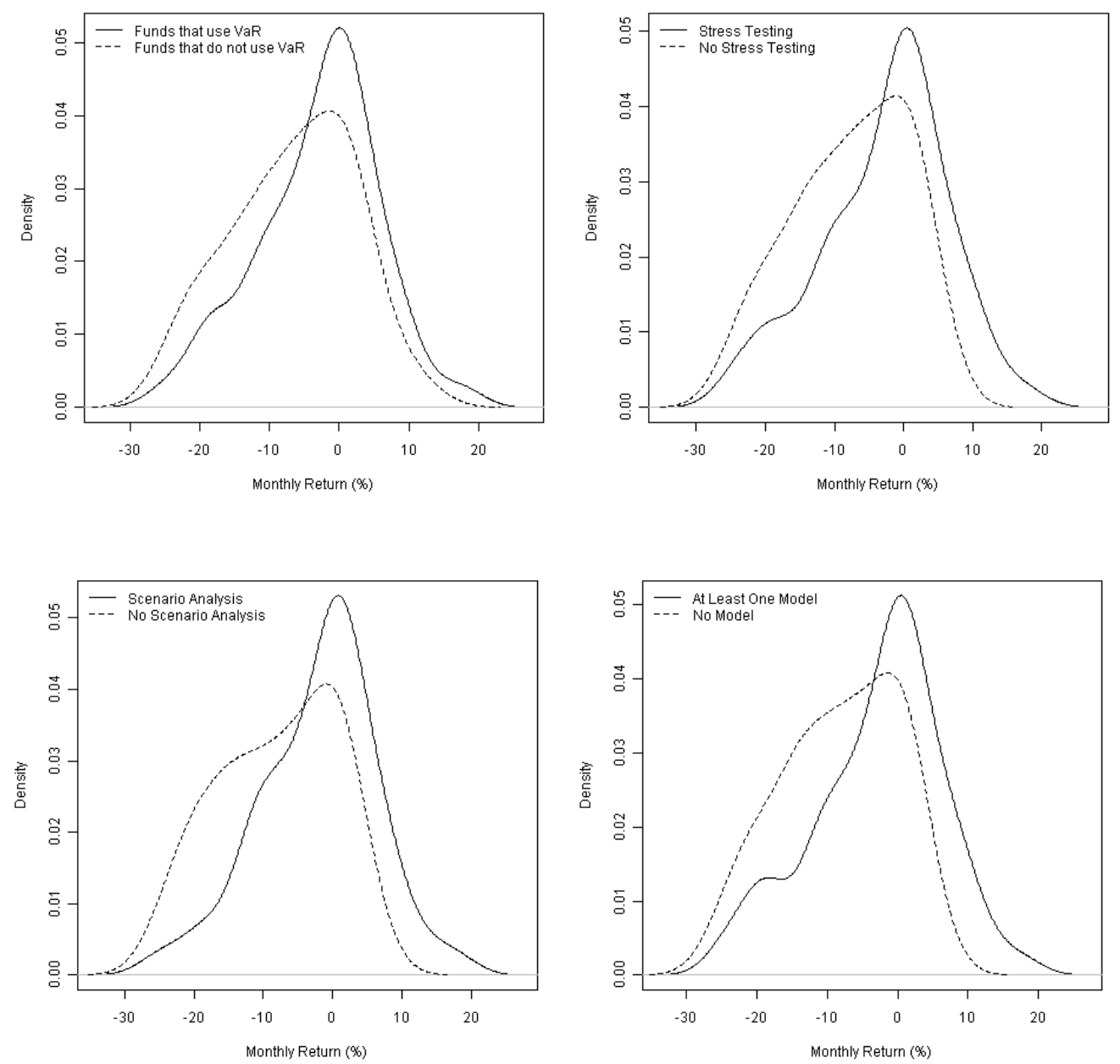


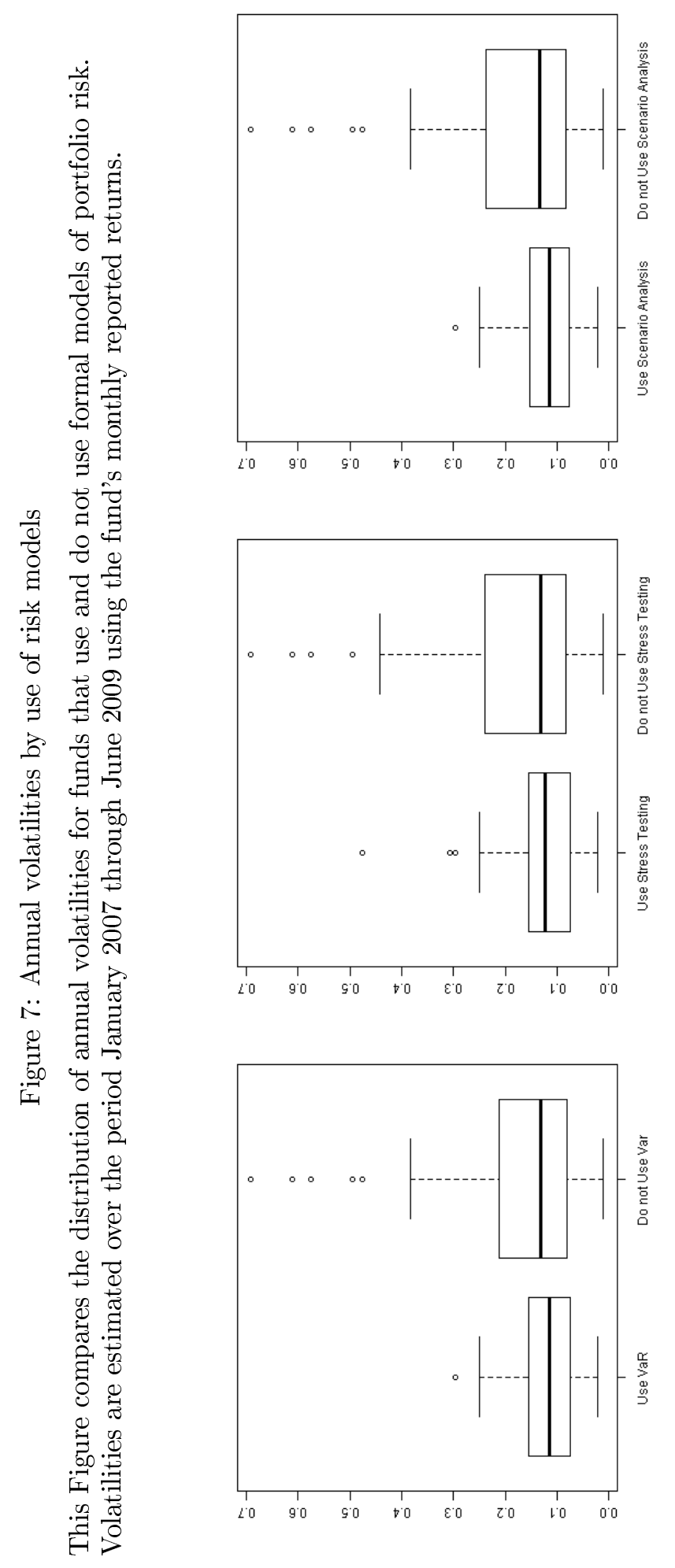




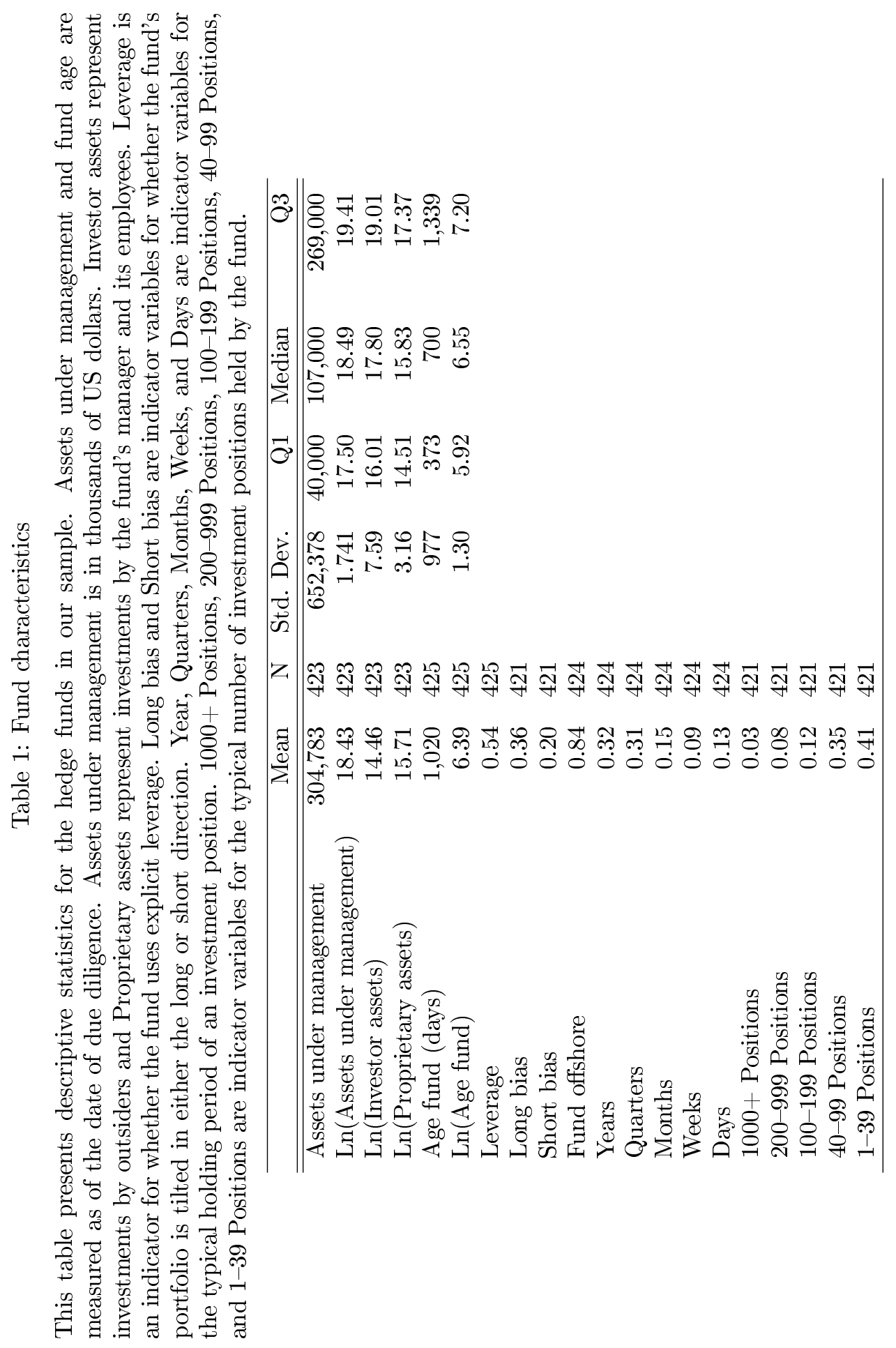


Table 2: Portfolio risk management practices

This table presents descriptive statistics for the portfolio risk management practices used by the funds in our sample.

\begin{tabular}{lcccc}
\hline & Full sample & \multicolumn{2}{c}{ With returns \& controls } \\
\hline & $\%$ & $\mathrm{~N}$ & $\%$ & $\mathrm{~N}$ \\
\hline \hline Portfolio risk models & & & & \\
Value at risk & 43.7 & 387 & 41.8 & 110 \\
Stress testing & 52.1 & 380 & 52.7 & 112 \\
Scenario analysis & 46.4 & 364 & 45.2 & 104 \\
At least one type & 58.3 & 393 & 56.3 & 112 \\
No models and testing & 47.0 & 349 & 48.0 & 102 \\
One type & 7.7 & 349 & 6.9 & 102 \\
Two types & 8.9 & 349 & 9.8 & 102 \\
All three types & 36.4 & 349 & 35.3 & 102 \\
& & & & \\
Head of risk management & & & & \\
Dedicated to risk management & 34.0 & 262 & 33.8 & 77 \\
No trading authority & 25.8 & 361 & 21.1 & 95 \\
Hedging authority only & 4.2 & 361 & 2.1 & 95 \\
Full trading authority & 70.1 & 361 & 76.8 & 95 \\
& & & & \\
Position limits & & & & \\
Hard limits & 16.6 & 427 & 19.3 & 114 \\
Guidelines & 26.9 & 427 & 28.1 & 114 \\
No limits & 56.4 & 427 & 52.6 & 114 \\
\hline
\end{tabular}




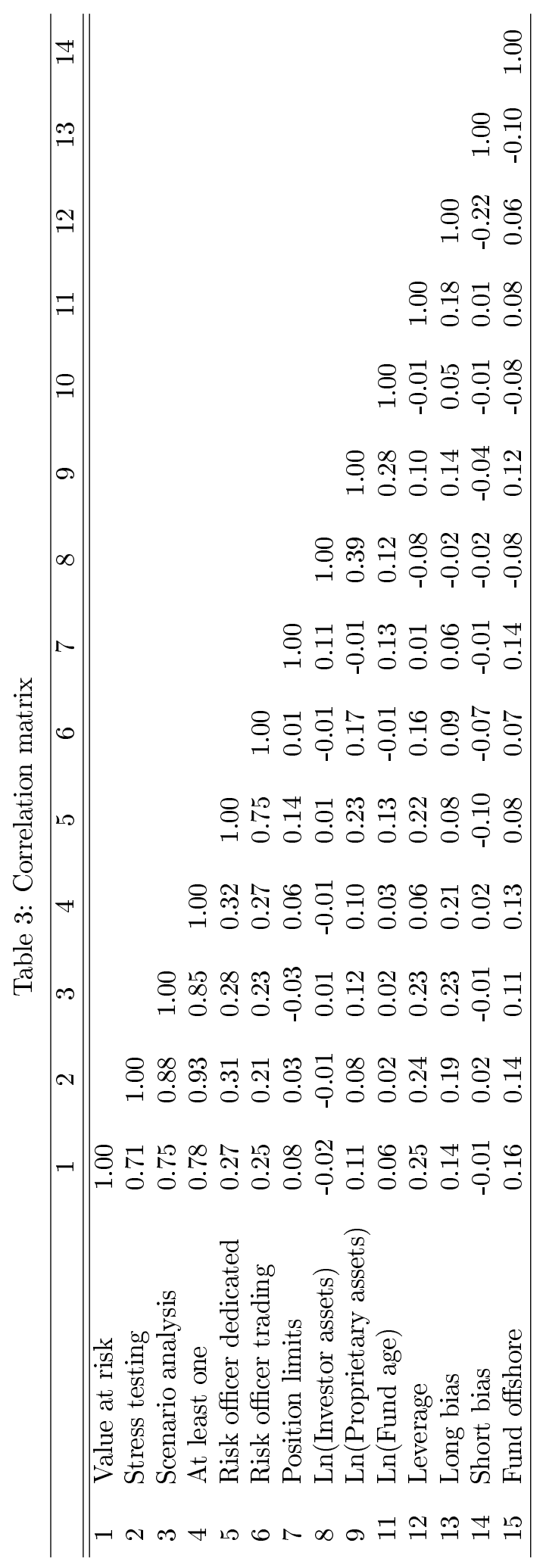


Table 4: Models of portfolio risk

This table presents results from tests of the determinants of portfolio risk models. The columns present marginal effects from probit regressions in which the dependent variable is coded as 1 if the fund uses the model type, and 0 otherwise. Standard errors are in parentheses.

\begin{tabular}{|c|c|c|c|c|}
\hline & Value at risk & Stress testing & Scenario analysis & At least one \\
\hline \multirow[t]{2}{*}{ Ln(Investor assets) } & 0.001 & 0.003 & -0.000 & 0.002 \\
\hline & $(0.004)$ & $(0.004)$ & $(0.004)$ & $(0.004)$ \\
\hline \multirow[t]{2}{*}{ Ln(Proprietary assets) } & 0.010 & 0.008 & 0.008 & 0.012 \\
\hline & $(0.010)$ & $(0.010)$ & $(0.010)$ & $(0.010)$ \\
\hline \multirow[t]{2}{*}{ Ln(Fund age) } & 0.008 & -0.017 & -0.011 & -0.007 \\
\hline & $(0.023)$ & $(0.023)$ & $(0.023)$ & $(0.022)$ \\
\hline \multirow[t]{2}{*}{ Leverage } & $0.184^{* * *}$ & $0.142^{* *}$ & $0.152^{* * *}$ & $0.170^{* * *}$ \\
\hline & $(0.057)$ & $(0.059)$ & $(0.057)$ & $(0.055)$ \\
\hline \multirow[t]{2}{*}{ Long bias } & $0.137^{* *}$ & $0.231^{* * *}$ & $0.194^{* * *}$ & $0.210^{* * *}$ \\
\hline & $(0.062)$ & $(0.061)$ & $(0.059)$ & $(0.056)$ \\
\hline \multirow[t]{2}{*}{ Short bias } & -0.012 & 0.027 & 0.052 & 0.050 \\
\hline & $(0.073)$ & $(0.075)$ & $(0.071)$ & $(0.068)$ \\
\hline \multirow[t]{2}{*}{ Fund offshore } & $0.233^{* * *}$ & 0.129 & $0.158^{* *}$ & $0.162^{* *}$ \\
\hline & $(0.068)$ & $(0.079)$ & $(0.078)$ & $(0.077)$ \\
\hline \multirow[t]{2}{*}{ Years } & $-0.221^{* *}$ & -0.151 & -0.149 & $-0.214^{* *}$ \\
\hline & $(0.091)$ & $(0.097)$ & $(0.098)$ & $(0.098)$ \\
\hline \multirow[t]{2}{*}{ Quarters } & $-0.186^{* *}$ & -0.086 & -0.041 & -0.120 \\
\hline & $(0.090)$ & $(0.096)$ & $(0.097)$ & $(0.098)$ \\
\hline \multirow[t]{2}{*}{ Months } & 0.017 & 0.112 & 0.082 & 0.018 \\
\hline & $(0.110)$ & $(0.111)$ & $(0.107)$ & $(0.108)$ \\
\hline \multirow[t]{2}{*}{ Weeks } & 0.070 & 0.062 & 0.113 & 0.074 \\
\hline & $(0.126)$ & $(0.133)$ & $(0.128)$ & $(0.120)$ \\
\hline \multirow[t]{2}{*}{ 1000+ Positions } & 0.147 & 0.256 & 0.102 & 0.134 \\
\hline & $(0.202)$ & $(0.187)$ & $(0.190)$ & $(0.183)$ \\
\hline \multirow[t]{2}{*}{ 200-999 Positions } & 0.172 & 0.140 & $0.297^{* * *}$ & $0.224^{* * *}$ \\
\hline & $(0.109)$ & $(0.111)$ & $(0.087)$ & $(0.086)$ \\
\hline \multirow[t]{2}{*}{ 100-199 Positions } & $0.237^{* * *}$ & $0.189^{* *}$ & $0.205^{* *}$ & $0.172^{* *}$ \\
\hline & $(0.089)$ & $(0.093)$ & $(0.083)$ & $(0.077)$ \\
\hline \multirow[t]{2}{*}{ 40-99 Positions } & $0.165^{* *}$ & 0.108 & 0.096 & $0.113^{*}$ \\
\hline & $(0.064)$ & $(0.065)$ & $(0.063)$ & $(0.060)$ \\
\hline Year fixed effects & Included & Included & Included & Included \\
\hline Observations & 369 & 350 & 364 & 376 \\
\hline p Value & 0.000 & 0.000 & 0.000 & 0.000 \\
\hline Log likelihood & -216.513 & -212.639 & -221.037 & -220.190 \\
\hline
\end{tabular}

${ }^{*} \mathrm{p}<.1,{ }^{* *} \mathrm{p}<.05,{ }^{* * *} \mathrm{p}<.01$, two-sided test 
Table 5: Head of risk management characteristics and responsibilities

This table presents results from tests of the determinants of characteristics and responsibilities of the head of risk management. The first column presents marginal effects from a probit regression in which the dependent variable is coded as 1 if the head of risk management is dedicated to risk management, and 0 otherwise. The second column presents coefficients from an ordered probit regression in which the dependent variable is coded as 2 if the head of risk management has no trading authority, 1 if he has hedging authority, and 0 if he has full trading authority. Standard errors are in parentheses.

\begin{tabular}{lcc}
\hline & Dedicated & Trading \\
\hline \hline Ln(Investor assets) & 0.007 & 0.013 \\
& $(0.006)$ & $(0.011)$ \\
Ln(Proprietary assets) & $0.056^{* * *}$ & $0.113^{* * *}$ \\
& $(0.020)$ & $(0.038)$ \\
Ln(Fund age) & 0.005 & $-0.137^{* *}$ \\
& $(0.031)$ & $(0.069)$ \\
Leverage & 0.085 & $0.283^{*}$ \\
& $(0.068)$ & $(0.164)$ \\
Long bias & -0.022 & 0.008 \\
& $(0.071)$ & $(0.164)$ \\
Short bias & -0.085 & -0.177 \\
& $(0.077)$ & $(0.201)$ \\
Fund offshore & 0.035 & 0.124 \\
& $(0.092)$ & $(0.228)$ \\
Years & 0.068 & 0.209 \\
& $(0.124)$ & $(0.266)$ \\
Quarters & $0.295^{* *}$ & 0.353 \\
& $(0.124)$ & $(0.257)$ \\
Months & $0.347^{* *}$ & $0.535^{*}$ \\
& $(0.145)$ & $(0.294)$ \\
Weeks & $0.385^{* *}$ & 0.074 \\
& $(0.152)$ & $(0.351)$ \\
1000+ Positions & $0.514^{* * *}$ & $0.658^{*}$ \\
& $(0.156)$ & $(0.390)$ \\
200-999 Positions & $0.239^{*}$ & $0.541^{*}$ \\
& $(0.142)$ & $(0.280)$ \\
100-199 Positions & 0.031 & 0.104 \\
& $(0.106)$ & $(0.245)$ \\
40-99 Positions & 0.060 & $0.338^{*}$ \\
& $(0.078)$ & $(0.179)$ \\
Year fixed effects & Included & Included \\
Observations & 256 & 344 \\
p Value & 0.000 & 0.001 \\
Log likelihood & -131.978 & -231.738 \\
\hline * $<.1, * *$ p $<.05, * * *$ & $p<.01$, two-sided test
\end{tabular}


Table 6: Limits on investment positions

This table presents results from tests of the determinants of position limits. It presents coefficients from an ordered probit regression in which the dependent variable is coded as 0 if the fund has no position limits, 1 if it has position guidelines, and 2 if it has hard limits. Standard errors are in parentheses.

\begin{tabular}{|c|c|}
\hline & Limits \\
\hline$\overline{\operatorname{Ln}(\text { Investor assets) }}$ & $\begin{array}{l}0.022^{* *} \\
(0.009)\end{array}$ \\
\hline Ln(Proprietary assets) & $\begin{array}{c}-0.002 \\
(0.023)\end{array}$ \\
\hline Ln(Fund age) & $\begin{array}{c}0.135^{* *} \\
(0.055)\end{array}$ \\
\hline Leverage & $\begin{array}{c}0.028 \\
(0.128)\end{array}$ \\
\hline Long bias & $\begin{array}{c}0.186 \\
(0.135)\end{array}$ \\
\hline Short bias & $\begin{array}{l}-0.013 \\
(0.158)\end{array}$ \\
\hline Fund offshore & $\begin{array}{c}0.566^{* * *} \\
(0.180)\end{array}$ \\
\hline Years & $\begin{array}{c}-0.457^{* *} \\
(0.214)\end{array}$ \\
\hline Quarters & $\begin{array}{c}-0.319 \\
(0.210)\end{array}$ \\
\hline Months & $\begin{array}{c}-0.781^{* * *} \\
(0.247)\end{array}$ \\
\hline Weeks & $\begin{array}{c}-0.331 \\
(0.274)\end{array}$ \\
\hline 1000+ Positions & $\begin{array}{c}-1.327^{* * * *} \\
(0.467)\end{array}$ \\
\hline 200-999 Positions & $\begin{array}{l}-0.254 \\
(0.246)\end{array}$ \\
\hline 100-199 Positions & $\begin{array}{l}-0.007 \\
(0.201)\end{array}$ \\
\hline 40-99 Positions & $\begin{array}{c}0.178 \\
(0.140)\end{array}$ \\
\hline Year fixed effects & Included \\
\hline $\begin{array}{l}\text { Observations } \\
\text { p Value }\end{array}$ & $\begin{array}{c}407 \\
0.000\end{array}$ \\
\hline Log likelihood & -372.333 \\
\hline
\end{tabular}




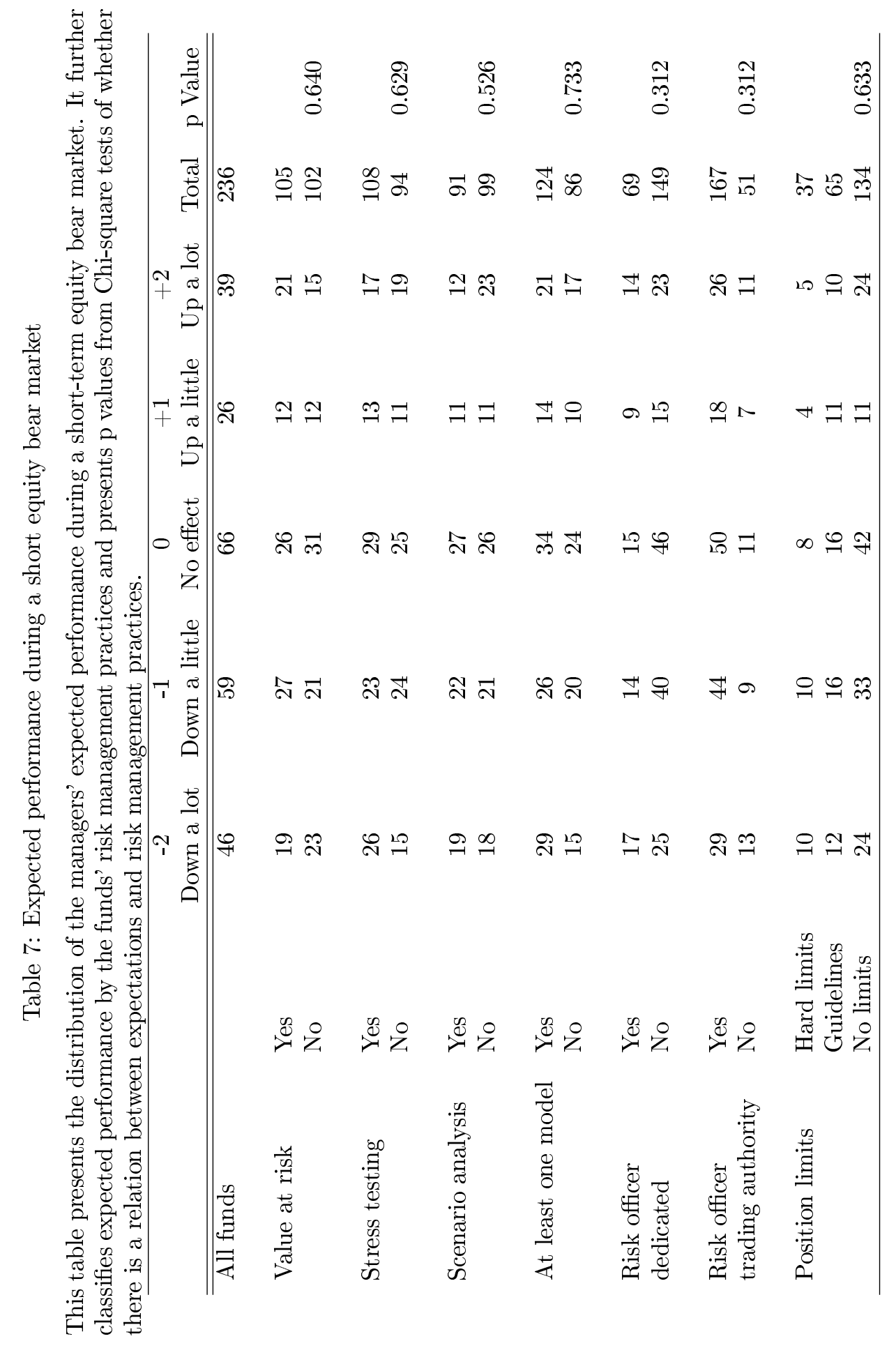




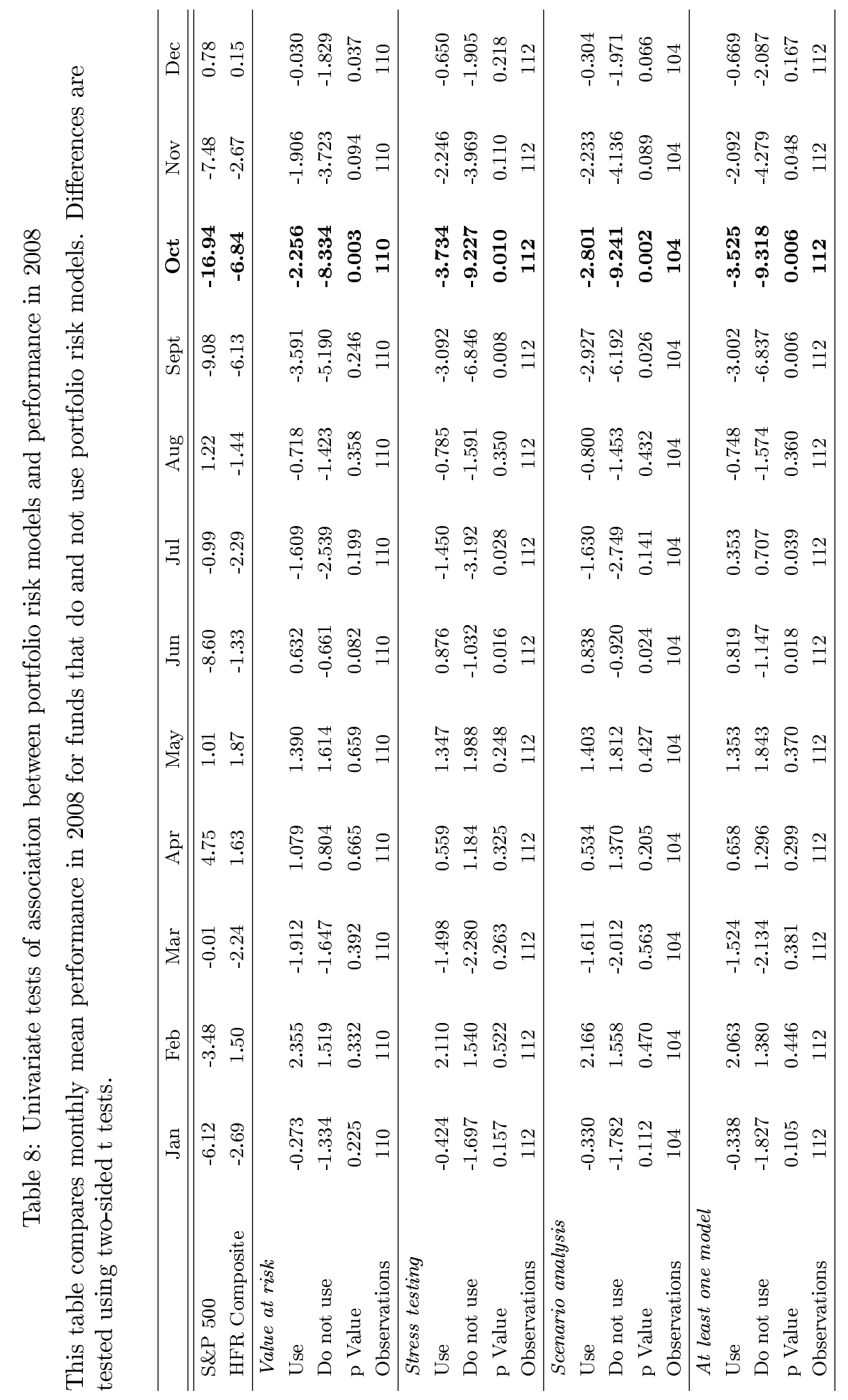




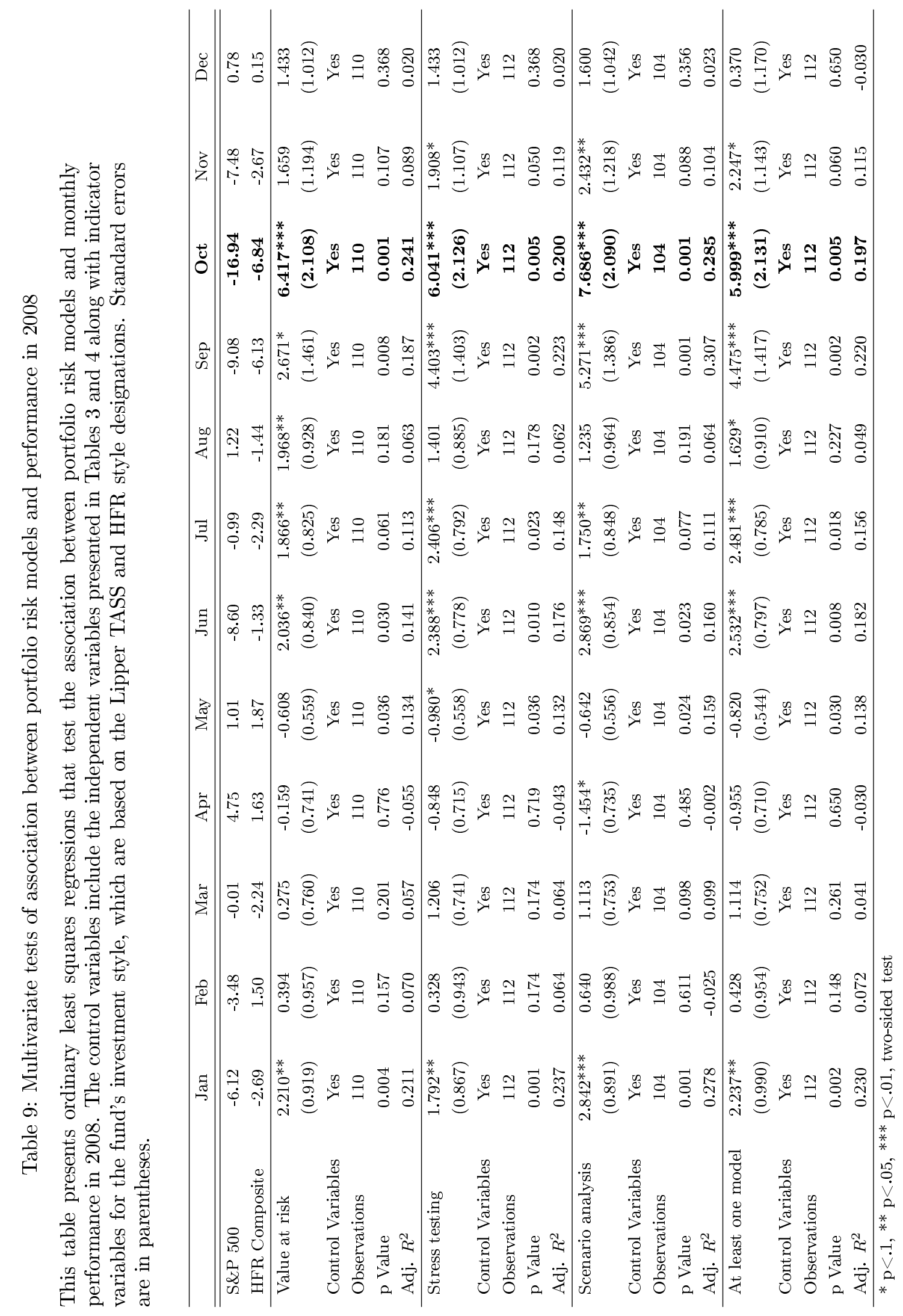




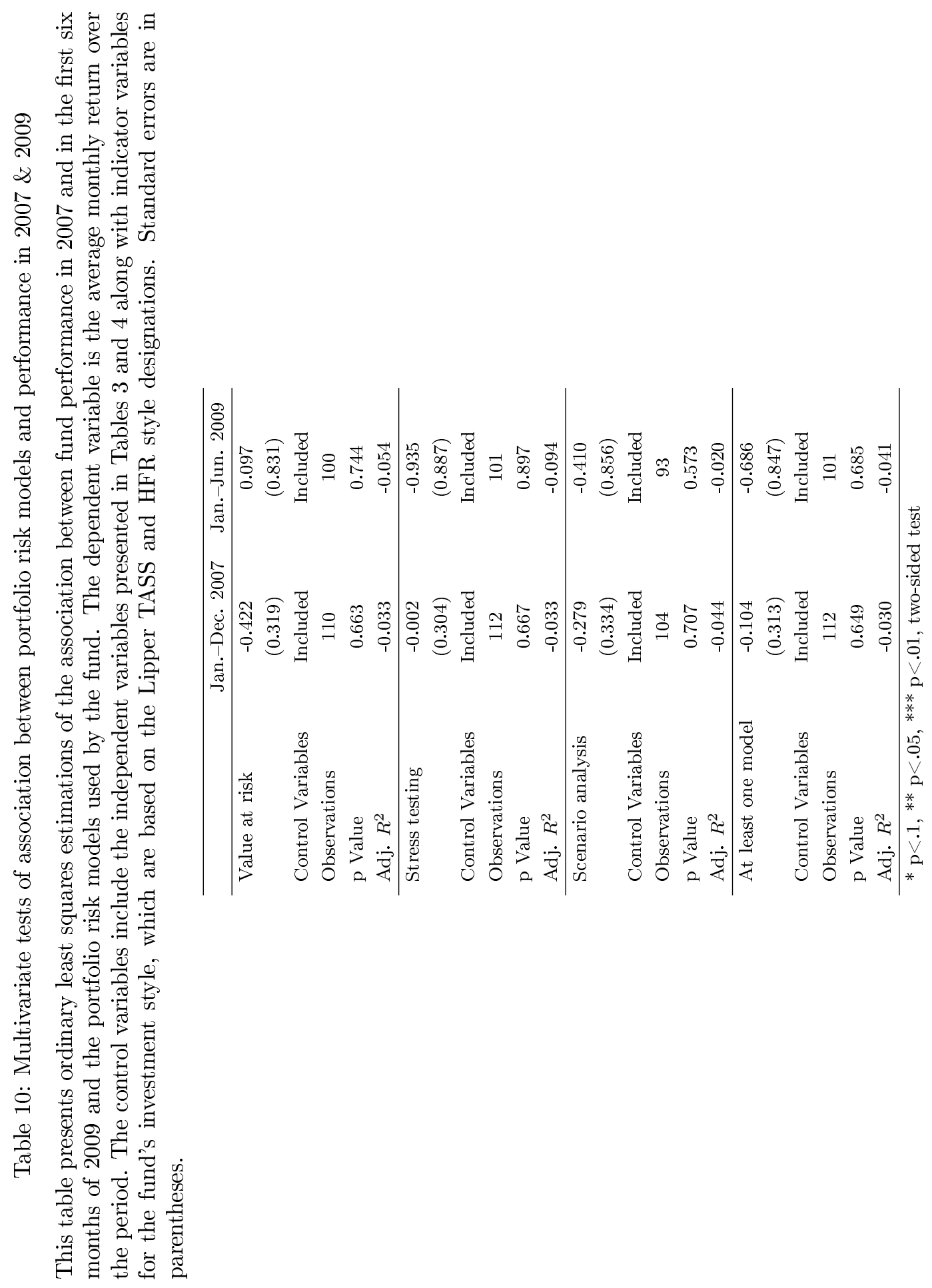




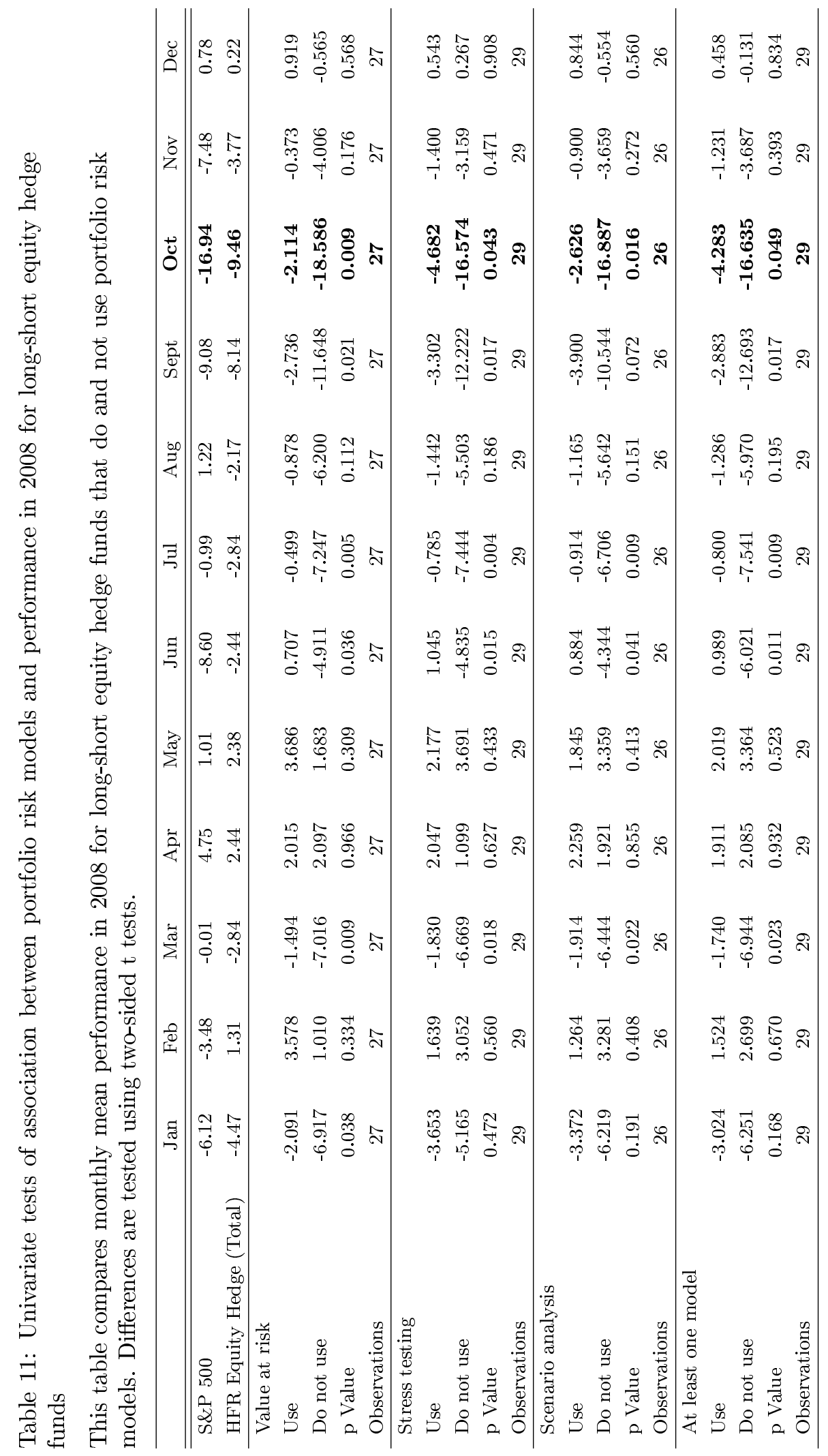




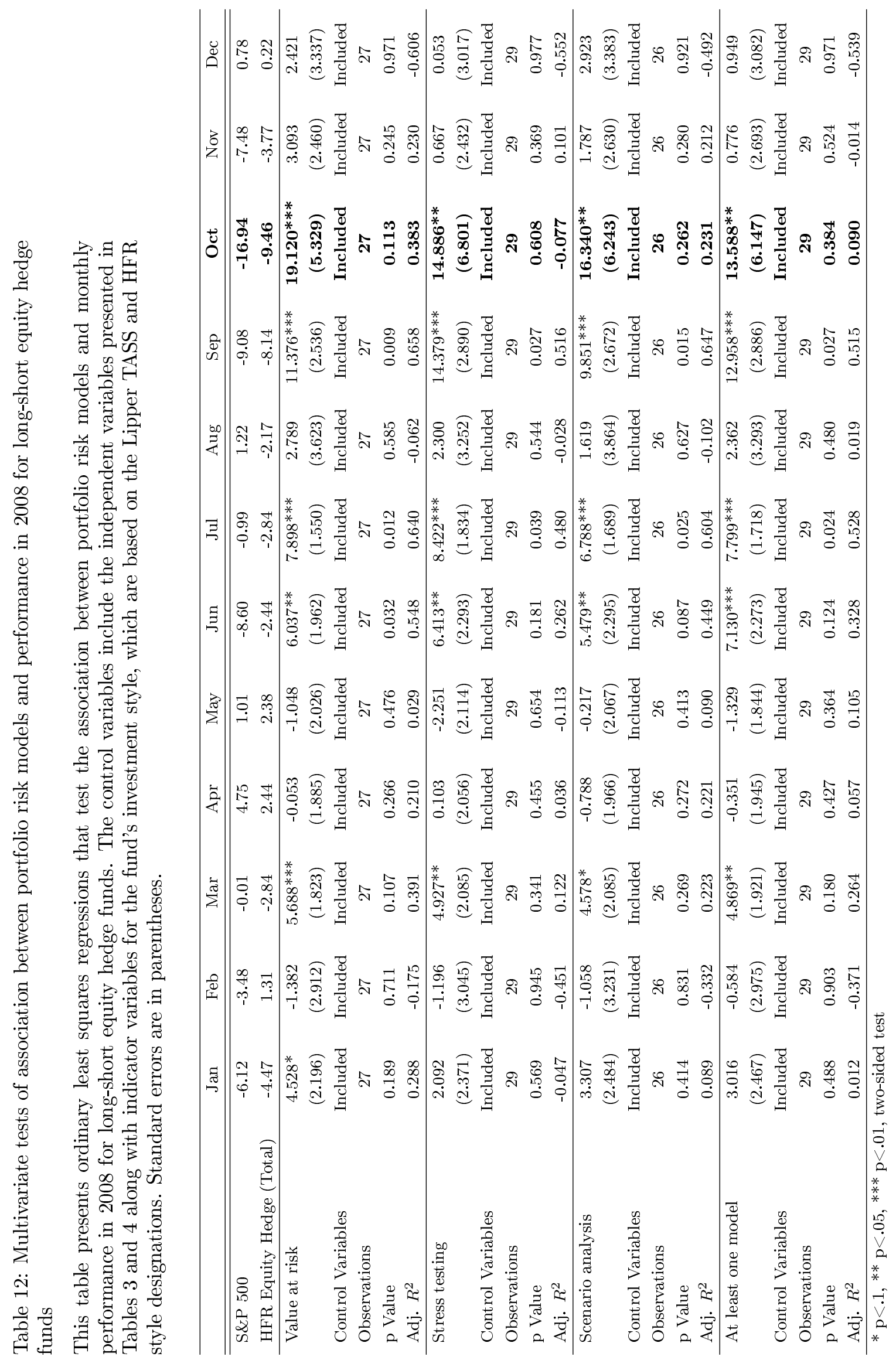




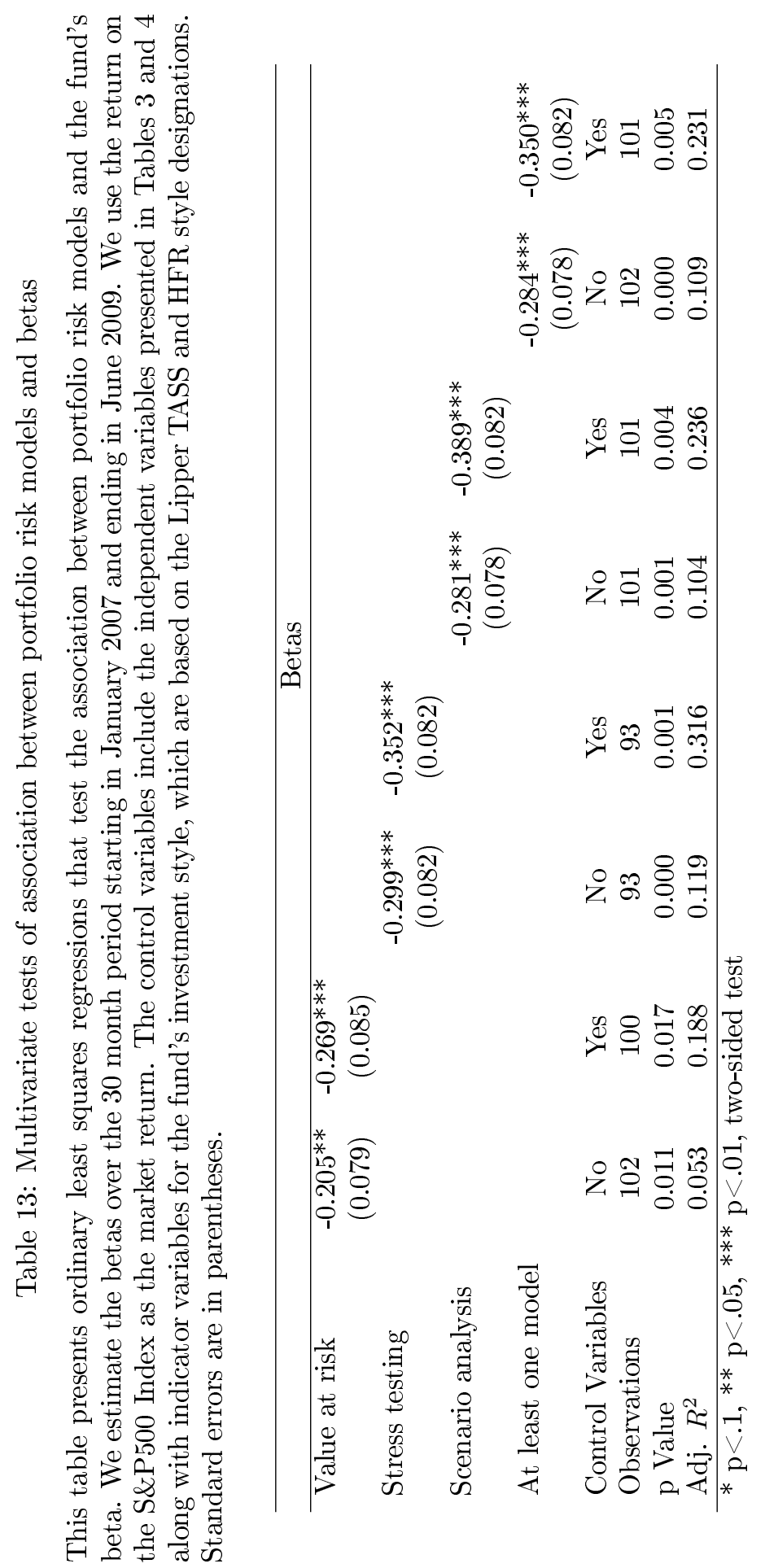

